\title{
Técnicas de cultivo de arroz irrigado: Relação com a qualidade de água, protozoários e diversidade fitoplanctônica
}

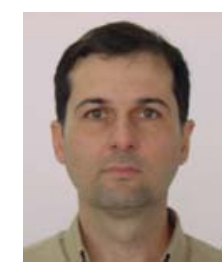

Ricardo D. Furtado ${ }^{1}$ \& Sérgio J. de Luca ${ }^{2}$

\author{
1 Centro do Ecologia/UFRGS. Av. Bento Gonçalves 9500, CEP 91501-970. Email: ricardo.furtado@vortex.ufrgs.br (Foto) \\ 2 IPH/UFRGS. Email: dlk@vortex.ufrgs.br
}

Protocolo 83 - 19/6/2002 - Aprovado em 14/4/2003

\begin{abstract}
Resumo: $O$ efeito de técnicas de cultivo do arroz irrigado sobre a qualidade da água efluente foi avaliado através de parâmetros físicos, químicos e biológicos. A pesquisa foi desenvolvida na Estação Experimental do Instituto Riograndense do Arroz (IRGA) no município de Cachoeirinha, RS, bacia do Rio Gravataí. Os testes foram realizados com 3 técnicas distintas e usuais de plantio: convencional, pré-germinado e direto. Constatou-se que, nos primeiros 30 dias de irrigação, os parâmetros medidos dentro dos quadros de plantio apresentaram valores superiores aos da entrada; após este período, a situação se inverteu. Com o crescimento, as plantas de arroz funcionaram como um banhado natural, extraindo da água e do solo uma quantidade significativa de nutrientes, não somente durante sua fase inicial, mas, também, durante todo o seu ciclo. Esses nutrientes foram extraídos do meio líquido, melhorando a qualidade ambiental da água efluente. Dentre todas as técnicas de cultivo, o menor impacto sobre a qualidade da água foi apresentado pelo plantio direto.
\end{abstract}

Palavras-chave: Oryza sativa L., qualidade ambiental, água de irrigação, técnicas de plantio

\section{Irrigated rice cultivation techniques: Relationship between water quality, protozoa and phytoplanktonic diversity}

\begin{abstract}
The purpose of this study was to evaluate the effect of techniques of rice cultivation on the physical, chemical and biological parameters of effluent water. The research was conducted at the Experimental Station of IRGA (Rio Grande do Sul Rice Institute), in the municipality of Cachoeirinha, RS, in the Gravataí river basin. The tests were performed using 3 usual techniques of rice cultivation, conventional, pre-germinated and direct planting. During the first 30 days of irrigation, the physical and chemical parameters of the paddy fields presented higher values compared to that of inflow. This shows that during this period the impact on water quality was highest. After this period, the situation changed completely. After reaching adult size, the rice plants acted as a natural swamp, extracting most of the contaminants from the water and the soil until the harvest. Thus the impact of rice farming is more concentrated during the first 30 days of irrigation was confirmed and it can be concluded that, depending on the cultivation technique used, there is efficient decontamination of the irrigation water. The most efficient technique was the direct planting.
\end{abstract}

Key words: irrigated rice, environmental quality, paddy fields water, irrigation water

\section{INTRODUÇÃO}

A cultura do arroz (Oryza sativa L.) irrigado é a maior consumidora agrícola de água em nível mundial e, em particular, no Rio Grande do Sul, devido ao grande percentual de áreas cultivadas por esta cultura serem irrigadas, provoca impactos desconhecidos sobre o meio aquático. O carreamento de nutrientes, tais como nitrogênio, fósforo e potássio e de agrotóxicos, que são lixiviados e conduzidos para o sistema de drenagem, origina a perda de recursos materiais e financeiros e agride a natureza, pois esses nutrientes e os defensivos agrícolas podem contaminar o meio ambiente, afetando as populações que fazem uso das águas dos corpos receptores.
Segundo o IRGA (1999), as principais técnicas de plantio do arroz no Rio Grande do Sul, são: plantio convencional, que consta do preparo do solo com aração e várias discagens, ou seja, uma movimentação muito intensa da camada superior do solo; plantio direto com pouca movimentação do solo e bem antecipado ao plantio, com o objetivo de usar um herbicida de ação total sobre o banco de inços que germinara no período entre o preparo do solo e o plantio e o plantio pré-germinado, que tem como característica principal o plantio da semente em um estágio inicial de germinação e no qual o preparo do solo é feito com as máquinas e implementos, trabalhando-se dentro do quadro de plantio totalmente inundado. 
O objetivo geral deste trabalho consiste em se comparar o efeito das três principais técnicas de cultivo do arroz irrigado no Rio Grande do Sul sobre a qualidade da água; para isto, foi realizada a avaliação do efeito das técnicas de plantio sobre os diversos parâmetros físicos, químicos e biológicos e do efeito das técnicas de plantio sobre a presença de protozoários parasitas humanos (Entamoeba histolytica, Giardia lamblia e Cryptosporidium parvum) geradores das doenças Amebíase, Giardíase e Cryptosporidíase.

\section{MATERIAL E MÉTODOS}

A pesquisa foi desenvolvida na Estação Experimental do Instituto Riograndense do Arroz no município de Cachoeirinha,RS, bacia hidrográfica do Rio Gravataí. Realizaram-se testes para se comparar a água de irrigação com a água dentro de cada sistema. Comparou-se, também, a água entre os sistemas de cultivo, cultivo convencional, cultivo prégerminado e cultivo direto. Cada quadro de cultivo tinha $1,150 \mathrm{~m}^{2}$ e o solo era homogêneo. A semente utilizada foi a BR IRGA 910 e foi adubada com a mesma quantidade de fertilizante, tanto na adubação de base (NPK) quanto na adubação de cobertura (uréia). As adubações de base foram feitas nos dias 20 e 27 de novembro de 2000; a adubação de cobertura foi dividida em duas aplicações, a primeira no dia 18 de dezembro de 2000 e a segunda no dia 9 de janeiro de 2001 . O tratamento com herbicidas e inseticidas foi diferente para cada forma de plantio, dependendo do manejo mais adequado. Os pontos de coleta foram identificado como de Rio-água de irrigação, rio Gravataí; PC - água do plantio convencional; PG - água do plantio pré-germinado e PD - água do plantio direto.

O sistema de irrigação foi feito com o objetivo de não haver perda de água por drenagem, buscando-se a máxima eficiência através da formação de um sistema fechado, em que as únicas perdas seriam via evapotranspiração e lixiviação.

Fizeram-se, ao todo, nove coletas de água nos $1^{\circ}, 4^{\circ}, 8^{\circ}$, $14^{\circ}, 25^{\circ}, 40^{\circ} 55^{\circ}$ e $68^{\circ}$ dias após o início da entrada da água nos quadros de irrigação. Uma última coleta foi realizada no $104^{\circ}$ dia após o início da irrigação, porém esta já havia sido desligada há 3 dias, com o intuito de se obter o grau de concentração dos nutrientes na lâmina d'água. Este período correspondeu de 15 de dezembro de 2000 a 29 de março de 2001.

A avaliação dos agrotóxicos foi realizada pelo teste de colinesterase, nos $1^{\circ}, 7^{\circ}, 13^{\circ} \mathrm{e} 104^{\circ}$ dias, após o início da irrigação nos quadros de plantio.

Usou-se, para análise do fósforo (ortofosfato) a cromatografia iônica, para o potássio, mercúrio $(\mathrm{Hg})$ e cromo $(\mathrm{Cr})$ a espectrofotometria de emissão, para o nitrogênio total o método de Kjeldahl, e a análise da colinesterase foi feita por reação enzimática e por medição da atividade, através de espectrofotometria visível, tendo este método uma sensibilidade de 0,01 ppm de Paration e precisão de $85 \%$. Para análise da densidade de coliformes totais e fecais, utilizou-se o método da membrana filtrante e para oxigênio dissolvido e $\mathrm{DBO}_{5}$ a titulometria pelo método de Winkler.

Em todas as análises de água e dos efluentes, seguiu-se o APHA (1995). As medições de condutividade, salinidade, turbidez e sólidos dissolvidos totais, foram feitos com medição direta com sonda multiparâmetros YSI (Yellow Spring Instruments).

A detecção dos protozoários foi realizada em 3 campanhas, nos $1^{\circ}, 24^{\circ}$ e $55^{\circ}$ dias após o enchimento completo de todos os quadros. Para cada amostra foram utilizados $20 \mathrm{~L}$ de água bruta filtrada com filtro $0,45 \mu \mathrm{m}$. O método utilizado para Cryptosporidium foi o de ZIEHL-NEELSEN, para Giardia e Ameba, o método da observação a fresco, pelo Laboratório de Microbiologia do Hospital das Clínicas da UFRGS.

A análise estatística dos dados foi realizada através de análise multivariada, como ferramenta para se tratar e interpretar o grau de correlação existente entre os diversos parâmetros e entre as unidades amostrais.

Os processos bióticos e abióticos que interagem dentro dos quadros plantados com arroz, contribuem para a formação de padrões estruturais, espaciais e temporais na comunidade aquática que se desenvolve dentro desses quadros irrigados artificialmente. Para se avaliar toda esta gama de interações e a variação quantitativa e qualitativa dos parâmetros, utilizou-se o software MULTIV(2.0) (Pillar, 2001); trata-se de um programa estatístico específico para análise multivariada, onde a entrada de dados feita através de matrizes, em cujas linhas devem ficar as variáveis e, nas colunas, as unidades amostrais, ou vice versa. O programa trabalha com dados qualitativos, quantitativos e mistos (Pillar, 2001).

A matriz original dos dados físicos, químicos e biológicos (coliformes totais e fecais) $29 \times 36$ foi reduzida para uma matriz $20 \times 16$, com o objetivo de diminuir ao máximo o efeito do ruído produzido pelas variáveis que tiveram comportamento mais independente do sistema.

Realizou-se uma transformação vetorial do tipo centralização e normalização dentro das variáveis. A medida de semelhança utilizada entre unidades amostrais foi a distância euclidiana. Para efetuar-se a ordenação das unidades amostrais escolheu-se a análise de coordenadas principais (PCoA) e, para o agrupamento, a soma dos quadrados (variância mínima).

Para análise do fitoplâncton utilizou-se uma matriz gerada pelos grupos genéricos 16 × 6, a qual também recebeu uma transformação vetorial dentro de variáveis tipo centralização e normalização. A medida de semelhança utilizada entre unidades amostrais foi a distância de corda. Para a ordenação usou-se PCoA e, para o agrupamento, a soma dos quadrados (variância mínima).

Empregou-se o teste de Mantel para analisar a correlação entre os aspectos físicos e químicos com os grupos de fitoplâncton e um nível de significância $(\alpha)$ menor que 5\%; já os grupos formados pela análise de agrupamento físico, químico e biológico foram comparados com o Índice de Qualidade de Água (IQA/NSF) modificado pela FEPAM (1995).

Índices de diversidade foram aplicados sobre as espécies encontradas de fitoplâncton. No total, realizaram-se 4 coletas em 4 unidades amostrais. Os índices de diversidade aplicados foram os Índices de Margalef (IM) e o de Shannon-Wiener (ISW) (Magurran, 1988). 


\section{RESULTADOS E DISCUSSÃO}

O nitrogênio é um elemento muito importante para o metabolismo de ecossistemas aquáticos, uma vez que participa da formação das proteínas, componente básico da biomassa dos organismos (Esteves, 1998). A Tabela 1 apresenta a distribuição da concentração de nitrogênio total $\left(\mathrm{mg} \mathrm{L}^{-1} \mathrm{de} \mathrm{N}\right)$ ao longo do tempo, nos três sistemas de cultivo. A dosagem de N é maior nos quadros irrigados que na água do Rio Gravataí, sendo que o plantio pré-germinado apresentou concentração superior às outras formas de plantio. Nota-se um súbito aumento na concentração de $\mathrm{N}$ na segunda amostra, do dia 18/12, devido à aplicação de $60 \mathrm{~kg} \mathrm{ha}^{-1}$ de uréia. Após esta data, as concentrações de $\mathrm{N}$ na água dos plantios começaram a diminuir, decrescendo a níveis menores que os alimentados pela água do rio.

O fósforo é fator limitante para a produtividade da aquaticofauna, uma vez que é fundamental para os processos metabólicos dos seres vivos, como o armazenamento de energia, estruturação da membrana celular e formação de mensageiros genéticos. Em ambientes eutrofizados artificialmente, o fósforo é responsável pela explosão populacional de espécies de fitoplâncton e de macrófitas aquáticas, principalmente em ambientes lênticos, como os quadros de arroz irrigado. O ortofosfato é o fósforo disponível para a biota aquática; por isto, é um importante parâmetro ambiental. A distribuição da concentração de ortofosfato $\left(\mathrm{mg} \mathrm{L}^{-1}\right.$ de $\left.\mathrm{PO}_{4}\right)$ é também apresentada na Tabela 1 . Na amostra da primeira coleta, a concentração de ortofosfato na água coletada dentro do quadro de plantio pré-germinado foi $247 \%$ maior que a água de irrigação; para o plantio convencional, foi $160 \%$ maior e, para o plantio direto, $137 \%$ maior. Esta diferença inicial reflete o manejo do solo para o plantio da cultura. As concentrações de ortofosfato dentro dos quadros de plantio vão gradativamente diminuindo ao longo do tempo de aguada, e na amostra da quinta coleta as concentrações de $\mathrm{PO}_{4}^{-3}$ já estão menores que na água de irrigação. Nas sétima e oitava amostras não se detectou a presença de ortofosfato nos plantios convencional e prégerminado e, no plantio direto, ocorreu concentração bem menor que a da água que entrou no sistema, indicando que o arroz está bioacumulando, além do que foi disponibilizado via adubação mineral, por retirada complementar deste nutriente da água que entra para irrigá-lo.

Quanto ao potássio (K) diz-se que ele é importante na função de estimulante da fotossíntese, regulando a intensidade de utilização de $\mathrm{CO}_{2}$ e aumentando a resistência a doenças fúngicas. Tem função imprescindível na transpiração foliar por ser um dos reguladores da abertura e fechamento dos estômatos. A Tabela 1 mostra a variação da concentração de potássio (mg L $\left.{ }^{-1} \mathrm{de} \mathrm{K}\right)$ ao longo do tempo. Inicialmente, na primeira amostra os valores em todos os pontos estão altos, inclusive aquele da água do rio; na segunda amostragem, a concentração de $\mathrm{K}$ diminui gradativamente em todos os sistemas, mesmo que a concentração de $\mathrm{K}$ da água de irrigação tenha aumentado, como ocorreu da terceira até a quinta amostra da água de irrigação. Pode-se inferir, então, que o arroz está bioacumulando, apesar do que foi disponibilizado para ele na adubação mineral e além do solo, também está retirando este nutriente da água de irrigação.

O método de medição da inibição da atividade da Colinesterase foi empregado para rastrear a presença de contaminação nas amostras por pesticidas organofosforados e carbamatos. Por este método, detectaram-se concentrações de 1,0, 5,0 e 1,0 ppm nas amostras do dia 15/12, no plantio convencional, plantio pré-germinado e plantio direto, respectivamente, não foi detectada na água de entrada. Na amostra do dia 22/12 não se detectou atividade colinesterásica nas amostras. Nas amostras do dia 28/12 detectou-se concentração de 0,5 ppm na água dos quadros do plantio pré-germinado e no plantio direto e, na do dia 29/03, novamente não se detectou atividade colinesterásica nas amostras (Tabela 2).

Tabela 2. Inibição da atividade colinesterásica nas águas de três sistemas de cultivo de arroz irrigado* e na água de irrigação

\begin{tabular}{ccccc}
\hline \multirow{2}{*}{ Data } & \multicolumn{4}{c}{ Colinesterase (ppm) } \\
\cline { 2 - 5 } & Rio & PC & PG & PD \\
\hline $15 / 12 / 2000$ & 0,0 & 1,0 & 5,0 & 1,0 \\
$22 / 12 / 2000$ & 0,0 & 0,0 & 0,0 & 0,0 \\
$28 / 12 / 2000$ & 0,0 & 0,0 & 0,5 & 0,5 \\
$29 / 03 / 2001$ & 0,0 & 0,0 & 0,0 & 0,0 \\
\hline
\end{tabular}

" PC - Plantio convencional; PG - Pré-germinado; PD - Plantio direto

Quanto à análise qualitativa de protozoários, não se detectou presença de Cryptosporidium parvum, Giardia lamblia e Entamoeba histolytica em nenhuma das amostras do rio nem das técnicas de cultivo.

Encontrou-se, na amostra de água efluente do PG do dia 15/12, uma turbidez elevada, 78,4 UNT (Tabela 3), fruto da técnica de preparo do solo para o posterior plantio, onde o trator revolve o solo encharcado, destruindo a camada superior

Tabela 1. Nitrogênio $(\mathrm{N})$, potássio $(\mathrm{K})$ e fosfato $\left(\mathrm{PO}_{4}^{-3}\right)$ nas águas de três sistemas de cultivo de arroz irrigado e na água de irrigação

\begin{tabular}{|c|c|c|c|c|c|c|c|c|c|c|c|c|}
\hline \multirow{2}{*}{ Data } & \multicolumn{4}{|c|}{ Nitrogênio Total - mg L ${ }^{-1}-\mathrm{N}$} & \multicolumn{4}{|c|}{ Potássio - mg L ${ }^{-1}-\mathrm{K}$} & \multicolumn{4}{|c|}{ Fosfato-ortofosfato - $\mathrm{mg} \mathrm{L}^{-1}-\mathrm{PO}_{4}{ }^{-3}$} \\
\hline & Rio & $\mathrm{PC}$ & PG & PD & Rio & $\mathrm{PC}$ & PG & PD & Rio & $\mathrm{PC}$ & PG & PD \\
\hline $15 / 12 / 2000$ & 2,8 & 3,9 & 5,1 & 3,1 & 2,29 & 2,25 & 2,33 & 1,50 & 0,47 & 1,23 & 1,64 & 1,12 \\
\hline $18 / 12 / 2000$ & 2,9 & 15,8 & 17,9 & 13,5 & 2,36 & 1,87 & 1,70 & 1,99 & 0,29 & 1,02 & 1,17 & 0,95 \\
\hline $21 / 12 / 2000$ & 3,3 & 8,6 & 14,9 & 8,9 & 0,58 & 1,62 & 1,62 & 2,34 & 0,38 & 0,88 & 0,91 & 0,74 \\
\hline $28 / 12 / 2000$ & 5,8 & 4,2 & 2,3 & 6,5 & 0,86 & 1,47 & 0,69 & 0,91 & 0,40 & 0,62 & 0,75 & 0,50 \\
\hline 08/01/2001 & 6,6 & 6,0 & 4 & 3,7 & 2,36 & 0,87 & 0,21 & 0,28 & 0,51 & 0,42 & 0,63 & 0,50 \\
\hline $23 / 01 / 2001$ & 3,3 & 2,4 & 6,2 & 5,8 & 0,65 & 0,14 & 0,17 & 0,19 & 0,34 & 0,24 & 0,29 & 0,26 \\
\hline $07 / 02 / 2001$ & 8,4 & 2,4 & 2,5 & 4,6 & 0,36 & 0,12 & 0,11 & 0,49 & 0,16 & 0,15 & 0,03 & 0,18 \\
\hline $20 / 02 / 2001$ & 3,2 & 3,8 & 2,6 & 6,7 & 0,37 & 0,19 & 0,13 & 0,52 & 0,26 & ND & ND & 0,23 \\
\hline $29 / 03 / 2001$ & - & - & - & - & 0,64 & 1,83 & 0,25 & 1,51 & 0,37 & ND & ND & ND \\
\hline
\end{tabular}

ND - Não detectado; PC - Plantio convencional; PG - Pré-germinado; PD - Plantio direto 
Tabela 3. Turbidez, condutividade elétrica e salinidade nas águas de três sistemas de cultivo de arroz irrigado* e na água de irrigação

\begin{tabular}{|c|c|c|c|c|c|c|c|c|c|c|c|c|}
\hline \multirow{2}{*}{ Data } & \multicolumn{4}{|c|}{ Turbidez (UNT) } & \multicolumn{4}{|c|}{ Condutividade Elétrica $\left(\mathrm{dS} \mathrm{m}^{-1}\right)$} & \multicolumn{4}{|c|}{ Salinidade $\left(\mathrm{g} \mathrm{L}^{-1}\right)$} \\
\hline & Rio & $\mathrm{PC}$ & PG & PD & Rio & PC & PG & PD & Rio & $\mathrm{PC}$ & PG & PD \\
\hline $15 / 12 / 00$ & 15,2 & 53,4 & 78,4 & 20,3 & 0,128 & 0,211 & 0,242 & 0,139 & 0,05 & 0,09 & 0,13 & 0,06 \\
\hline $18 / 12 / 00$ & 14,2 & 23,7 & 40,1 & 15,1 & 0,129 & 0,163 & 0,270 & 0,265 & 0,06 & 0,07 & 0,12 & 0,12 \\
\hline $21 / 12 / 00$ & 16,8 & 17,5 & 22,3 & 14,3 & 0,140 & 0,190 & 0,270 & 0,260 & 0,10 & 0,11 & 0,13 & 0,10 \\
\hline $28 / 12 / 00$ & 13,9 & 15,1 & 18,3 & 10,1 & 0,224 & 0,168 & 0,162 & 0,195 & 0,10 & 0,07 & 0,07 & 0,08 \\
\hline 08/01/01 & 14,9 & 14,5 & 17,1 & 7,5 & 0,216 & 0,132 & 0,145 & 0,120 & 0,10 & 0,06 & 0,07 & 0,05 \\
\hline 23/01/01 & 17,6 & 12,1 & 16,8 & 6,3 & 0,091 & 0,036 & 0,035 & 0,056 & 0,04 & 0,01 & 0,01 & 0,02 \\
\hline $07 / 02 / 01$ & 17,1 & 10,9 & 16,9 & 6,4 & 0,093 & 0,033 & 0,030 & 0,080 & 0,04 & 0,01 & 0,01 & 0,03 \\
\hline 20/02/01 & 16,2 & 11,2 & 17,0 & 6,9 & 0,084 & 0,073 & 0,064 & 0,088 & 0,04 & 0,03 & 0,03 & 0,04 \\
\hline $29 / 03 / 01$ & 15,1 & 10,5 & 17,5 & 6,9 & 0,132 & 0,131 & 0,115 & 0,130 & 0,06 & 0,06 & 0,05 & 0,06 \\
\hline
\end{tabular}

deste e deixando a água com quantidade expressiva de elementos suspensos; já o PD, onde houve pouca movimentação do solo, apresentou valor bem menor, 20,3 UNT. A água efluente do PC ficou em uma situação intermediária 53,4 UNT, porém todos com valores maiores que da água bruta do rio, com 15,2 UNT. Na segunda amostragem a turbidez diminuiu aproximadamente $48,8 \%$ na água efluente do $\mathrm{PG}, 55,6 \%$ no PC e $24,6 \%$ no PD, sendo que na água bruta do rio ocorreu variação de $6 \%$ mostrando, após o plantio, uma sedimentação rápida de grande parte da matéria suspensa, permanecendo colóides em suspensão. Os dados obtidos a partir da amostra do dia 28/12, indicam que a sedimentação dentro dos quadros se estabilizou, pois desta data em diante a variação de turbidez foi pequena. $\mathrm{O}$ quadro estabilizado mostra que a turbidez da água no PD foi aproximadamente $60 \%$ menor que a turbidez do rio, enquanto a turbidez da água no PG foi bastante próxima da água bruta do rio, e os valores do $\mathrm{PC}$ giraram entre os dos $\mathrm{PD}$ e PG, porém inferiores ao do rio.

Quanto à salinidade observou-se, nas três primeiras coletas, uma concentração maior de sais na água efluente dos quadros de cultivo que na água bruta do Rio, captada do rio Gravataí. A partir da coleta do dia 28/12, o sistema inverteu-se: a salinidade nos quadros ficou menor que a d'água do rio (Tabela 3); este comportamento da dinâmica da salinidade foi conseqüência direta da solubilização dos adubos minerais que ainda estavam disponíveis no solo, e da entrada da água bruta do rio, pelo início da irrigação. Esses sais ficaram solúveis na lâmina d'água e disponíveis para o arroz, tanto que, com o crescimento da planta, a sua demanda continuou provocando diminuição da concentração de sais nos quadros de cultivo, ainda que estivesse entrando uma concentração maior na água bruta do rio, isto é, os sais foram absorvidos pelo sistema, parte via bioacumulação, e parte adsorvida pelos colóides do solo. Comparando-se as técnicas de plantio encontrou-se, nas três primeiras coletas, uma concentração maior de sais na água efluente do PG, conseqüência direta da forma da adubação que a técnica requer, já que a mesma foi feita com a lâmina d'água já estabelecida. A partir da coleta do dia 28/12, as concentrações decrescem bastante, até que, na coleta do dia 29/3, ocorreu um ligeiro aumento, devido à diminuição da lâmina d'água que gerou aumento da concentração salina na mesma.

Observando-se a Tabela 3 nota-se, nas três primeiras coletas, uma condutividade elétrica maior dentro dos quadros de cultivo que na água bruta do rio. A partir da coleta do dia 28/12, a situação inverteu-se: a condutividade elétrica nas águas efluentes dos quadros ficou menor que a da água bruta do rio; nota-se, também, que, independente do aumento da condutividade na água bruta do rio nos dias 28/12 e 08/01 com 0,224 e 0,216 mS $\mathrm{cm}^{-1}$, respectivamente, um decréscimo progressivo da condutividade nas águas efluentes dos quadros de plantio, indicando que o sistema reteve os íons, via bioacumulação ou adsorção nos colóides do solo. Comparando-se a água efluente dos quadros de cultivo, observou-se que nas primeiras três amostragens a condutividade foi maior na água efluente do PG, indicando que a forma de plantio mais impactante foi a do plantio pré-germinado, que produziu uma liberação de íons maior que as outras técnicas. Constatou-se, também, nas duas últimas amostragens, aumento na condutividade, conseqüência direta da diminuição da lâmina d'água, que provocou uma concentração de íons na camada, aumentando a sua condutividade.

As concentrações de cromo, apresentadas em todas as amostras coletadas no ciclo de irrigação ficaram abaixo do nível de detecção pelo espectrofotômetro, que é de $0,01 \mathrm{mg} \mathrm{L}^{-1} \mathrm{de}$ $\mathrm{Cr}^{3+}$ e mostra que, à montante do ponto de captação da água bruta do rio, há baixo impacto industrial de empresas que usam o cromo em seu processo industrial ou, ainda, que não há o uso de insumos contaminados com esse metal, no processo da implantação da lavoura.

As médias calculadas da concentração de mercúrio das unidades amostrais, foram: rio, $3,83 \mu \mathrm{g} \mathrm{L}^{-1}$; $\mathrm{PC} 1,82 \mu \mathrm{g} \mathrm{L}{ }^{-1}$; $\mathrm{PG}$ 1,67 $\mu \mathrm{g} \mathrm{L}^{-1}$ e PD 2,27 $\mu \mathrm{g} \mathrm{L} \mathrm{L}^{-1}$. Comparando-se essas médias constata-se que a mais alta corresponde à água bruta do rio, a segunda mais elevada foi a detectada na água efluente do PD, seguida pela do plantio convencional e, finalmente, a menor média foi encontrada no plantio pré-germinado (Tabela 4). Observa-se, também, que durante o ciclo de irrigação na lavoura a água bruta do rio esteve sempre com uma concentração de mercúrio maior que as encontradas nas águas efluentes dos quadros de cultivo, com exceção dos dados do dia 29/3, pelos motivos já descritos anteriormente. As águas do PC e PG apresentaram valores mais elevados de todas as unidades amostrais. Deve-se lembrar que o limite do CONAMA 20/86 para a classe 3 é de $2,0 \mu \mathrm{g} \mathrm{L}{ }^{-1} \mathrm{de} \mathrm{Hg}$. Fazendo-se uma comparação entre as águas efluentes dos quadros de cultivo, observou-se que o PD apresentou a maior média de todas as formas de cultivo, enquanto a água do efluente do PG apresentou a menor, ficando a água do plantio convencional com concentrações intermediárias. 
Tabela 4. Concentração de mercúrio $\left(\mu g \mathrm{~L}^{-1} \mathrm{de} \mathrm{Hg}\right)$ nas águas de três sistemas de cultivo de arroz irrigado* e na água de irrigação

\begin{tabular}{ccccc}
\hline Data & Rio & PC & PG & PD \\
\hline $15 / 12 / 2000$ & 4,3 & 2,7 & 1,9 & 2,2 \\
$18 / 12 / 2000$ & 9,8 & 1,4 & 1,8 & 1,6 \\
$21 / 12 / 2000$ & 4,4 & 1,9 & 2,3 & 3,9 \\
$28 / 12 / 2000$ & 4,2 & 2,5 & 1,9 & 1,6 \\
$08 / 01 / 2001$ & 1,9 & 1,6 & 1,4 & 1,6 \\
$23 / 01 / 2001$ & 5,2 & 1,1 & 1,6 & 5,3 \\
$07 / 02 / 2001$ & $<0,1$ & $<0,1$ & $<0,1$ & $<0,1$ \\
$20 / 02 / 2001$ & 3,0 & 2,8 & 2,0 & 2,9 \\
$29 / 03 / 2001$ & 1,6 & 2,3 & 2,0 & 1,3 \\
Média & 3,83 & 1,82 & 1,67 & 2,27 \\
\hline
\end{tabular}

" PC - Plantio convencional; PG - Pré-germinado; PD - Plantio direto

A Tabela 5 evidencia que a densidade populacional média e o desvio padrão de coliformes totais e fecais são maiores na água do rio que na água das técnicas de plantio, entre as quais o plantio direto foi o que apresentou menor densidade média e menor desvio-padrão. Nos quadros, por sua profundidade muito pequena, a radiação solar penetra fortemente em toda a lâmina d'água, provocando efeito antimicrobiano contribuindo, assim, para a redução das populações de microrganismos sensíveis à luz ultravioleta.

A Tabela 6 mostra que a menor média e o menor desvio padrão da DBO e de OD foram encontrados no plantio direto. O modo de preparo do solo com o uso de herbicidas de ação total e a decomposição da palhada dentro da lâmina d'água afetam a produção e a demanda de oxigênio no meio.

\section{Correlações entre os dados físicos e químicos}

Para análise de ordenação, utilizaram-se os dois primeiros eixos, em que o primeiro responde por $44,14 \%$ e o segundo por $15,50 \%$ do total da variação de todos os descritores. A análise realizada com o 'software' MULTIV mostrou que há significância amostral, pois o eixo 1 é estável, para um $\alpha=0,05$. Os eixos $1 \mathrm{e}$ 2 , juntos, respondem por $59,64 \%$ do total da variação, mostrando ser um valor razoável para 2 eixos (Pillar, 2001).

Fazendo-se uma análise das variáveis para o eixo 1, nota-se que foram a condutividade $(\mathrm{Co}=-0,946438)$, a salinidade $(\mathrm{As}=$ $-0,919576)$, o ortofosfato $\left(\mathrm{PO}_{4}^{-3}=-0,882127\right)$, a turbidez $(\mathrm{Tu}=$ $-0,867701)$ e o potássio $(\mathrm{K}=0,857701)$ as variáveis que melhor descreveram o sistema, pois ficaram com valores acima de 0,85 da variação no eixo, e que todas as correlações são negativas, indicando decréscimo das concentrações ao longo do eixo 1, da esquerda para a direita; portanto, há um gradiente negativo das primeiras coletas em direção às posteriores, indicando diminuição nas concentrações dos elementos no tempo.

O eixo 1 representa a variação de qualidade da água no tempo. A ordenação mostrou uma nítida tendência de melhora da qualidade da esquerda para a direita. O efeito do tempo de irrigação também foi notado, pois no início da irrigação verificou-se qualidade inferior da água, ao passo que no final do período da irrigação, a água efluente dos quadros apresentou melhora substancial.

Para o agrupamento, o teste de significância mostra que há formação nítida de 3 grupos (Figura 1); cortando-se o dendrograma no ponto onde a soma dos quadradros dentro

Tabela 5. Densidade populacional de coliformes totais e coliformes fecais nas águas de três sistemas de cultivo de arroz irrigado* e na água de irrigação

\begin{tabular}{|c|c|c|c|c|c|c|c|c|}
\hline \multirow{2}{*}{ Data } & \multicolumn{4}{|c|}{ Coliformes Totais - NMP $100 \mathrm{~mL}^{-1}$} & \multicolumn{4}{|c|}{ Coliformes Fecais - NMP $100 \mathrm{~mL}^{-1}$} \\
\hline & Rio & $\mathrm{PC}$ & PG & PD & Rio & $\mathrm{PC}$ & PG & PD \\
\hline $18 / 12 / 2000$ & 7000 & 4500 & 3800 & 2000 & 5200 & 3100 & 2700 & 1200 \\
\hline $21 / 12 / 2000$ & 5500 & 3200 & 3500 & 2000 & 4000 & 2800 & 3200 & 1400 \\
\hline $28 / 12 / 2000$ & 6000 & 1500 & 1500 & 1000 & 4400 & 1200 & 1200 & 800 \\
\hline $23 / 01 / 2001$ & 2700 & 2400 & 1500 & 1000 & 2000 & 1000 & 800 & 500 \\
\hline 07/02/2001 & 2000 & 600 & 1900 & 300 & 1000 & 400 & 1000 & 200 \\
\hline $20 / 02 / 2001$ & 1190 & 1000 & 500 & 1700 & 1000 & 500 & 400 & 1000 \\
\hline $29 / 03 / 2001$ & 2100 & 1840 & 1500 & 2500 & 1900 & 920 & 1200 & 1900 \\
\hline Média & 3784 & 2149 & 2028 & 1957 & 2786 & 1417 & 1500 & 1000 \\
\hline Desvio Padrão & 2313 & 1349 & 1189 & 1605 & 1717 & 1086 & 1037 & 568 \\
\hline
\end{tabular}

*PC - Plantio convencional; PG - Pré-germinado; PD - Plantio direto

Tabela 6. Demanda bioquímica de oxigênio (DBO) e oxigênio dissolvido (OD) nas águas de três sistemas de cultivo de arroz irrigado* e na água de irrigação

\begin{tabular}{|c|c|c|c|c|c|c|c|c|}
\hline \multirow{2}{*}{ Data } & \multicolumn{4}{|c|}{$\mathrm{DBO}-\mathrm{mg} \mathrm{L}^{-1}$} & \multicolumn{4}{|c|}{$\mathrm{OD}-\mathrm{mg} \mathrm{L}^{-1}$} \\
\hline & Rio & $\mathrm{PC}$ & PG & PD & Rio & $\mathrm{PC}$ & PG & PD \\
\hline $15 / 12 / 2000$ & 2,47 & 2,11 & 0,83 & 1,66 & 6,14 & 6,53 & 2,57 & 5,14 \\
\hline $18 / 12 / 2000$ & 2,27 & 11,00 & 9,29 & 6,71 & 2,48 & 11,41 & 10,74 & 6,92 \\
\hline $21 / 12 / 2000$ & 6,40 & 9,50 & 6,82 & 3,93 & 6,61 & 9,92 & 8,26 & 4,13 \\
\hline $28 / 12 / 2000$ & 0,99 & 8,55 & 5,89 & 2,79 & 1,03 & 9,30 & 8,68 & 3,10 \\
\hline $08 / 01 / 2001$ & 1,64 & 3,93 & 4,13 & 2,27 & 1,86 & 4,13 & 4,54 & 2,48 \\
\hline $23 / 01 / 2001$ & 1,65 & 3,93 & 9,30 & 2,07 & 1,65 & 3,92 & 9,29 & 2,07 \\
\hline $07 / 02 / 2001$ & 2,02 & 2,07 & 5,17 & 2,07 & 2,84 & 2,07 & 5,16 & 2,07 \\
\hline $20 / 02 / 2001$ & 1,65 & 2,07 & 2,27 & 2,07 & 1,86 & 2,48 & 2,69 & 2,48 \\
\hline $29 / 03 / 2001$ & 3,10 & 3,93 & 1,86 & 1,65 & 5,17 & 4,13 & 5,99 & 5,99 \\
\hline Média & 4,39 & 5,23 & 5,06 & 2,80 & 3,29 & 5,99 & 6,41 & 3,82 \\
\hline Desvio Padrão & 5,99 & 3,49 & 3,09 & 1,62 & 2,10 & 3,44 & 2,98 & 1,82 \\
\hline
\end{tabular}

* PC - Plantio convencional; PG - Pré-germinado; PD - Plantio direto 
das variáveis (Sqdentro) é 6,0, vê-se a configuração dos grupos e as unidades amostrais que estão mais próximas.

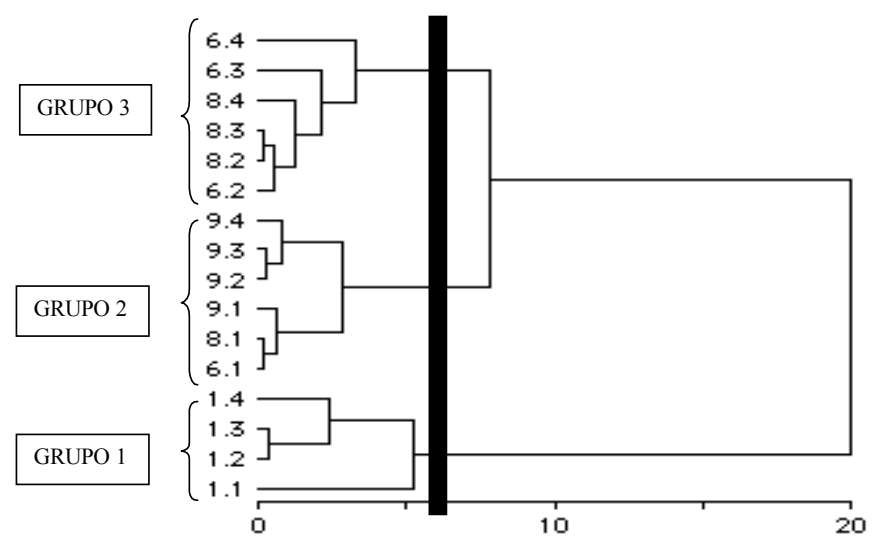

Numeração das unidades amostrais, o primeiro dígito corresponde à amostragem (1-primeira; 6-Sexta; 8-oitava e 9-nona amostragem) e o segundo à técnica de plantio e à água de irrigação (1-Rio; 2-PC; 3PG e 4-PD)

Figura 1. Dendrograma obtido através da análise de semelhança com distância euclidiana pelo método da soma dos quadrados, realizada com dados físicos, químicos e coliformes fecais e totais transformados vetorialmente por centralização e normalização, formando grupos de maior semelhança na qualidade da água entre as unidades amostrais de três sistemas de cultivo de arroz irrigado e a água de irrigação

O padrão gerado pelo agrupamento mostrou que os parâmetros físicos e químicos se agruparam tanto pelo período da coleta quanto pela técnica de plantio utilizada.

O grupo 1 foi formado por todas as unidades amostrais da primeira amostragem, realizada no dia $15 / 12$, em que a água bruta do rio e a água efluente do PC, do PG e do PD, mostram que as condições iniciais dos sistemas têm características semelhantes.

O grupo 2 foi formado pelas unidades amostrais da água bruta do rio (coletas de 30, 60 e 90 dias) e pelas coletas do último dia de água efluente das técnicas de plantio, mostrando que as condições finais da água nas diversas formas de plantio se assemelham com as condições gerais da água do rio.

Ao se cortar o grupo 2, no ponto onde Sq dentro é igual a 2,5 , ver-se-á que existe a formação de dois subgrupos, nos quais as unidades do rio se agrupam separadamente das unidades amostrais formadas pela água efluente dos plantios no final do ciclo de irrigação.

O grupo 3 foi formado pelas unidades amostrais das coletas intermediárias (30 e 60 dias) no PC, PG e PD. Neste agrupamento, ficaram de fora as unidades amostrais compostas pela água bruta do rio, indicando que as características deste é diferente das características das águas efluentes dos quadros de irrigação.

\section{Ocorrência de fitoplâncton nos quadros de cultivo}

Quanto ao fitoplâncton utilizaram-se, para análise de ordenação, os dois primeiros eixos, em que o primeiro responde por $41,47 \%$ e o segundo por $25,79 \%$; somados, ambos res- pondem por $67,26 \%$ do total da variação de todos os descritores.

Fazendo-se uma análise das variáveis para o eixo 1, nota-se que os grupos Chlorophyta $(\mathrm{Ch}=-0,826)$, Bacillariophyta $(\mathrm{Ba}=-0,814)$, Cyanophyta $(\mathrm{Cy}=0,729)$, Cryptophyta $(\mathrm{Ct}=$ $-0,474)$, Euglenophyta $(\mathrm{Eu}=0,228)$ e Dinophyta $(\mathrm{Di}=-0,2009)$ foram os mais representatívos. Observa-se que Chlorophyta, Bacillariophyta, Cryptophyta e Dinophyta têm correlações negativas, indicando decréscimo das populações ao longo do eixo 1, da esquerda para a direita; portanto, há um gradiente negativo das primeiras coletas em direção às posteriores, mostrando decréscimo dessas populações, com o maior tempo de irrigação; já os grupos Cyanophyta e Euglenophyta têm correlação positiva, indicando aumento das populações, ao longo do eixo 1, da esquerda para a direita, e que essas populações estão aumentando com o maior tempo de irrigação, melhor adaptadas ao sistema lêntico. As espécies de Cyanophytas mais freqüentes foram Nostoc sp., Pseudoanabaena sp., Planktolyngbya limnetica e Oscillatoria brevis.

Para o agrupamento, o teste de significância mostra que houve formação nítida de quatro grupos (Figura 2). Cortandose o dendrograma no ponto 4,0, ver-se-á a configuração dos grupos e as unidades amostrais que estão mais próximas.

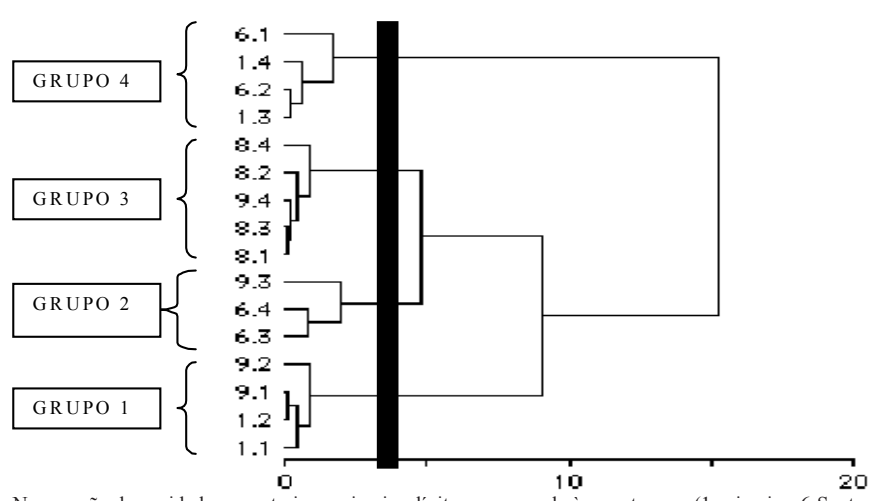

Numeração das unidades amostrais, o primeiro dígito corresponde à amostragem (1-primeira; 6-Sexta; 8-oitava e 9-nona amostragem) e o segundo à técnica de plantio e à água de irrigação (1-Rio; 2-PC; 3 PG e 4-PD)

Figura 2. Dendrograma obtido através da análise de semelhança com distância de corda pelo método da soma dos quadrados e transformação vetorial com centralização e normalização das variáveis realizadas com dados dos grupos de fitoplâncton, formando grupos de maior semelhança de espécies fitoplanctônicas entre as unidades amostrais de três sistemas de cultivo de arroz irrigado e a água de irrigação

O padrão gerado pelo agrupamento mostrou que as populações de fitoplâncton se agruparam tanto pelo período da coleta quanto pelo da forma de plantio.

O grupo 1 foi formado pelas unidades amostrais do primeiro dia de coleta de água (com a água bruta do rio e com a água efluente do PC) e do último dia de coleta ( $90^{\circ}$ dia de irrigação) também do rio e do plantio convencional; já o grupo 2 foi formado pelas unidades amostrais do PG nas coletas dos $30^{\circ} \mathrm{e}$ 
$60^{\circ}$ dias e na amostra de água efluente do PD do $60^{\circ}$ dia; por sua vez, o grupo 3 foi constituído pelas unidades amostrais da coleta $\left(60^{\circ}\right.$ dia de irrigação) tanto do rio quanto nos outras formas de plantio e, também, na amostra de água efluente do $\mathrm{PD}$, aos $60^{\circ}$ dia de irrigação; enfim, o grupo 4 foi composto pelas coletas do primeiro dia nos $\mathrm{PG}$ e PD e das coletas do $30^{\circ}$ dia da água bruta do Rio e da água efluente do PC, demonstrando que há evolução e substituição das populações durante todo o ciclo de irrigação.

O teste de Mantel mostrou correlação entre os grupos de fitoplâncton e os fatores abióticos de 0,2507, e o teste de aleatoriedade, um valor de 0,007 ( $<<0,05)$.

\section{Avaliação dos efluentes por índices}

Observando-se a Tabela 7 verifica-se que o valor do índice de qualidade da água (IQA) dos quadros de plantio foi, em geral, superior ao da água bruta do rio. Somente na primeira amostragem do dia 15/12, o IQA do rio foi superior ao da água efluente dos quadros de plantio, refletindo o fato de que o preparo do solo teve grande importância e impactou a qualidade da água mais fortemente, no momento inicial do período de irrigação.

Tabela 7. Indice de qualidade de água (IQA) das unidades amostrais*

\begin{tabular}{ccccc}
\hline Data & Rio & PC & PG & PD \\
\hline 15/12/2000 & 46 & 44 & 33 & 47 \\
$23 / 01 / 2001$ & 48 & 55 & 58 & 51 \\
$20 / 02 / 2001$ & 49 & 55 & 53 & 51 \\
29/03/2001 & 55 & 53 & 59 & 63 \\
Máximo & 55 & 55 & 59 & 63 \\
Mínimo & 46 & 44 & 33 & 47 \\
Média & 49 & 52 & 51 & 53 \\
Desvio Padrão & 3,70 & 5,2 & 12,0 & 6,9 \\
\hline PC - Plantio convencional; PG - Pré-germinado; PD - Plantio direto & &
\end{tabular}

A primeira coleta indica que o IQA da água efluente dos quadros de plantio foi menor em relação ao da água bruta do rio, principalmente a do $\mathrm{PG}(\mathrm{IQA}=33)$, refletindo o impacto da fase de plantio, que foi o pior momento, onde o trabalho de gradagem sobre o solo saturado gera um aspecto visual muito ruim da água. Os outros tipos de plantio, por sua forma menos impactante no solo, mostraram um IQA um pouco maior. O PC mostrou ter qualidade um pouco melhor com um IQA igual a 44 e o PD, o mais alto IQA, entre todas as técnicas de plantio, com 47.

O comportamento do IQA da amostragem no dia 23/1 demonstrou uma melhora apreciável da qualidade da água em relação à primeira. Há de ser notado que a maior melhora foi a do PG, pois seu IQA subiu a 58. O IQA de todas as amostras da água efluente dos quadros demonstrou melhora da qualidade da água, pois o do PC foi de 55 e do PD de 51.

A amostragem do dia 20/2 demonstrou que a qualidade da água efluente nos quadros de irrigação apresentou ligeira queda no PG, com 53. No PC e PD mantiveram-se praticamente constantes, com 55 e 51, respectivamente. Nota-se que o IQA do rio continuou inferior ao dos quadros de irrigação.
O IQA da quarta e última amostragem apontou para uma melhora da qualidade da água no PD, que atingiu valor igual a 63, e o PG com 59. Somente a qualidade do PC teve uma ligeira queda em relação à da amostra anterior, com IQA igual a 53.

O Índice de Margalef (IM) é usado para medir o grau de riqueza do ambiente e pode ser visto na Tabela 8 , que mostra a variação no tempo e no espaço da riqueza da população fitoplantônica durante o ciclo de irrigação da lavoura de arroz.

Tabela 8. Índice de Margalef (IM) nas unidades amostrais na cultura de arroz irrigado*

\begin{tabular}{ccccc}
\hline Data & Rio & PC & PG & PD \\
\hline 15/12/2000 & 7,4 & 4,5 & 3,5 & 5,3 \\
$23 / 01 / 2001$ & 4,0 & 4,0 & 3,0 & 3,3 \\
20/02/2001 & 4,3 & 2,8 & 3,5 & 3,3 \\
29/03/2001 & 4,3 & 3,2 & 2,9 & 3,5 \\
Máximo & 7,4 & 4,5 & 3,5 & 5,3 \\
Mínimo & 4,0 & 2,8 & 2,9 & 3,3 \\
Média & 4,9 & 3,6 & 3,0 & 3,8 \\
Desvio Padrão & 1,6 & 0,7 & 0,4 & 0,9 \\
\hline PC - Plantio convencional; PG - Pré-germinado; PD - Plantio direto & &
\end{tabular}

Notou-se maior riqueza na água bruta do rio que na água efluente dos quadros de irrigação, durante todo o ciclo de irrigação.

A primeira amostragem refletiu a água mais impactada pelo trabalho de plantio com a aração e a aplicação de defensivos agrícolas, mostrando menor diversidade no PG, exatamente aquele que tem seu solo mais danificado, devido à forma de seu preparo; já o IM indica que o PC e o PD tiveram comportamento semelhante pois, inicialmente, esteve com um IM maior que o da segunda amostragem e, a partir desta, houve estabilização na riqueza de espécies, dentro desses quadros.

Nas coletas subseqüentes, o IM melhorou, mostrando que ocorreu aumento da quantidade de espécies durante todo o ciclo. Na última coleta, notou-se piora da qualidade, havendo também recuo do IM. Utilizando-se o Índice de Shannon-Wiener (ISW) como um indicativo para avaliar o grau de poluição hídrica e se comparando esses valores com os propostos por Jhinam et al. (1989) vê-se que os valores apresentados na Tabela 9 são baixos, todos muito próximos de 1,0 , indicando que a água é poluída para valores menores que $1,0(<1,0)$ ou moderadamente poluída, quando os valores estão entre 1,0 e 3,0 .

Fazendo-se uma média entre as unidades amostrais, verificou-se que o rio apresenta média do ISW maior que a dos quadros de plantio, considerando-se todo o ciclo de irrigação.

Tabela 9. Índice de Shannon-Wiener (ISW) nas unidades amostrais na cultura de arroz irrigado*

\begin{tabular}{ccccc}
\hline Data & Rio & PC & PG & PD \\
\hline 15/12/00 & 1,49 & 1,18 & 1,07 & 1,10 \\
$23 / 01 / 01$ & 0,89 & 1,27 & 0,94 & 0,99 \\
$20 / 02 / 01$ & 1,20 & 1,04 & 1,11 & 1,01 \\
$29 / 03 / 01$ & 1,09 & 0,98 & 1,08 & 1,20 \\
Máximo & 1,49 & 1,27 & 1,11 & 1,20 \\
Mínimo & 0,89 & 0,97 & 0,94 & 0,98 \\
Média & 1,17 & 1,16 & 1,05 & 1,07 \\
Desvio-Padrão & 0,25 & 0,13 & 0,08 & 0,09 \\
\hline PC - Plantio convencional; PG - Pré-germinado; PD - Plantio direto & &
\end{tabular}


Dentre as técnicas de plantio, o PC foi o que apresentou a maior média $(1,16)$ seguida pela do $\mathrm{PD}(1,07)$. A menor média foi do PG $(1,05)$. Nota-se que a diferença entre eles foi pequena e, se compará-los com os limites propostos por Jihnan (op. cit.) poder-se-á dizer que as águas são moderadamente contaminadas.

Pela análise da diversidade fitoplantônica, o maior ISW foi encontrado no dia 15/12, na água bruta do rio, com 1,49 e a menor diversidade no dia 23/01, também no rio (ISW $=0,89$ ); isto significa que houve maior amplitude no rio que nos quadros de irrigação e, sendo assim, os quadros apresentaram maior estabilidade ambiental que no corpo receptor.

\section{CONCLUSÕES}

1. Durante todo o ciclo de irrigação, houve um primeiro momento, até $\mathrm{o} 30^{\circ}$ dia aproximadamente em que os teores dos parâmetros de qualidade da água foram superiores às concentrações destes na água de entrada. Após um período que se estendeu do $20^{\circ}$ ao $40^{\circ}$ dia de irrigação, a concentração desses parâmetros dentro dos quadros foi menor que da água de alimentação, estabelecendo-se um sistema fechado (efluente zero) sem fuga de água.

2. Ocorreu decréscimo sensível da atividade colinesterásica ao longo do tempo nas três formas de cultivo, não havendo predominância de uma sobre as demais.

3. Comparando-se a qualidade da água efluente das diferentes técnicas de plantio, notou-se que a melhor qualidade está presente na água efluente do PD (IQA médio igual a 53). Durante todo o ciclo da irrigação, a pior qualidade foi obtida na água efluente do PG (IQA médio igual a 50,75).

4. A qualidade da água na fase inicial de irrigação (primeiros 30 dias) é muito baixa, mas quanto maior o período transposto, maior também será a melhora da qualidade.
5. Não foram detectados protozoários patogênicos na água de irrigação nem nos efluentes.

6. Constatou-se substituição de populações de fitoplâncton, influenciada pela mudança que a água sofre do sistema lótico para o sistema lêntico e pela influência física e química da água resultante das técnicas de plantio, diminuindo a diversidade de espécies.

7. A cultura do arroz, dependendo da técnica de cultivo, apresenta comportamento semelhante a um banhado artificial, pois é notável a redução de coliformes, de nutrientes (ortofosfato, nitritos, nitratos) e de defensivos agrícolas, tornando as águas efluentes melhores que as de irrigação original.

\section{LITERATURA CITADA}

APHA - American Public Health Association. Standard methods for the examination of water and wastewater. Washington, 1995. 1268p.

Esteves, F.de A. Fundamentos de limnologia. 2.ed. Rio de Janeiro: Interciência, 1998. 575p.

FEPAM - Fundação Estadual de Proteção Ambiental Luis Roessler. Qualidade das águas do rio Gravataí: período 1992/ 1994. Porto Alegre, 1995. 66p.

IRGA - Instituto Riograndense do Arroz. Arroz irrigado: recomendações técnicas da pesquisa para o sul do Brasil. Pelotas, 1999. 126p.

Jhinam, V.G., Ahmad, S. H., Singh,A.K., Application of ShannonWiever Index as a measure of pollution of River Ganga, at Patna, Bihar. Current Science, New Delhi, v.58, n.13, p.717-720,1994.

Magurran, A.E. Ecological diversity and its measurement. New Jersey:Princeton University Press, 1988. 179p.

Pillar, V. de P. Estatística -análise multivariada. Porto Alegre: PPGECO, 2001. 